\title{
Application of diffusion tensor imaging for the diagnosis of segmental level of dysfunction in cervical spondylotic myelopathy
}

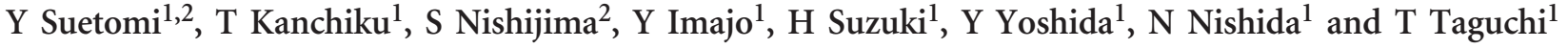

Study Design: A retrospective study.

Objectives: Diffusion tensor imaging (DTI) reflects pathological change in the spinal cord more sensitively than conventional magnetic resonance imaging (MRI). Electrophysiological examination enables quantitative assessment of spinal cord function. Few studies have addressed the correlation between intraoperative spinal cord-evoked potentials (SCEPS) and DTI. The purpose of this study was to examine whether DTI is an objective index for the diagnosis of the segmental level of dysfunction in cervical spondylotic myelopathy (CSM).

Setting: Yamaguchi University Graduate School of Medicine, Japan.

Methods: Using 3.0-Tesla MRI, DTI values for the apparent diffusion coefficient (ADC) and fractional anisotropy (FA) were measured at the disc level C2/C3 through C6/C7 in 11 normal subjects and 10 subjects with CSM. Subjects with CSM were divided into two groups based on the extent of compression according to conventional MRI: single level $(n=3)$ and multilevel $(n=7)$. Intraoperative SCEPs were measured in subjects with CSM. For each group, the ADC and FA values were compared with SCEPs with respect to the segmental levels of dysfunction.

Results: For all three subjects with single-level compression and six of seven with multilevel compression, the maximal ADC value was observed at the segmental level of dysfunction as per the SCEP. Minimum FA values were observed at those sites in two of three patients with single-level compression and in only two of seven with multi-level compression.

Conclusion: Our results suggest that ADC might serve as a supplementary diagnostic indicator of the segmental levels of dysfunction in CSM.

Spinal Cord (2016) 54, 390-395; doi:10.1038/sc.2015.192; published online 27 October 2015

\section{INTRODUCTION}

Cervical spondylotic myelopathy (CSM) is diagnosed using magnetic resonance imaging (MRI) and neurological examination. However, the neurological findings are not always typical, and clinical symptoms of CSM may differ between patients. Determination of the segmental levels of spinal cord involvement in CSM can be difficult, particularly in cases involving multi-level compression. In addition, the presence of high-signal intensity lesions on T2-weighted MRI of the cervical spinal cord does not necessarily correspond to myelopathy. Spinal cord-evoked potentials (SCEPs) measured by electrophysiological examination are useful for investigating the functional integrity of the spinal cord, even in cases involving compression at several levels.

Diffusion tensor MR imaging (DTI) is an advanced MRI technique that measures the diffusion of water molecules in tissues. Objective and quantitative assessment of microstructural change is possible by means of DTI.

Useful DTI parameters include the apparent diffusion coefficient (ADC) and fractional anisotropy (FA). The ADC reflects the diffusive strength of water molecules, regardless of directionality. ADC values thus increase in compressed lesions of the spinal cord. ${ }^{1}$ FA measures the directional diffusion of water molecules, which is prescribed by axon structure. Normal white matter has abundant nerve fibers, whereas gray matter has few. Thus, the FA values of the gray matter are smaller than those of white matter. Decreased FA values reflect a loss of anisotropic diffusion of water molecules, indicating damage and degeneration of tract fibers in compressed sites of spinal cord. ${ }^{2}$

Several studies report the use of DTI for the diagnosis of early-stage CSM and indicate a correlation between DTI values and prognosis following surgery. ${ }^{3,4}$ However, these studies have not investigated the correlation between segmental levels of dysfunction and the values of DTI parameters.

The aim of present study was to consider whether DTI parameters are an objective indicator of segmental level involvement in CSM as determined by means of SCEPs. We compared the results of intraoperative SCEPs, a quantitative measure of spinal cord function, with $\mathrm{FA}$ and $\mathrm{ADC}$ values.

\section{MATERIALS AND METHODS}

The study was approved by the Institutional Review Board of Yamaguchi University Hospital and adhered to the tenets of the Declaration of Helsinki.

${ }^{1}$ Department of Orthopaedic Surgery, Yamaguchi University Graduate School of Medicine, Yamaguchi, Japan and ${ }^{2}$ Department of Orthopaedic Surgery, St. Hill hospital, Yamaguchi, Japan

Correspondence: Dr Y Suetomi, Department of Orthopedic Surgery, Yamaguchi University Graduate School of Medicine, 1-1-1 Minami-Kogushi, Ube, Yamaguchi 755-8505, Japan.

E-mail ysuetomi0902@yahoo.co.jp

Received 7 October 2014; revised 1 July 2015; accepted 16 September 2015; published online 27 October 2015 


\section{Subjects}

Normal subjects. Eleven normal subjects, three men and eight women, with a mean age of 68.6 years (range 56-87) were enrolled. All considered themselves to be healthy, and none had a history of neck injuries, neurological disorders. The absence of cervical spinal cord compression was confirmed on MRI for all subjects.

Subjects with cervical spondylotic myelopathy. Ten consecutive patients with clinical signs and symptoms of chronic cervical spinal cord compression (six men and four women; mean age, 71.8 years; range, 60-82) were enrolled in this study.

\section{Clinical assessment}

Diagnosis of myelopathy was established based on the presence of hyperreflexia, upper extremity sensory disturbance and motor examination of muscles. ${ }^{5}$ The findings on neurological examination of each CSM subject were shown in Table 1. In addition, to evaluate the severity of CSM we assess muscle strength, gait disorder and bladder function. The Japanese Orthopedic Association scoring system for cervical myelopathy was employed (Table 2). The Japanese Orthopedic Association score quantifies neurological impairment by evaluating upper extremity function (4 points), lower extremity function (4 points), sensibility (6 points) and urinary bladder function ( 3 points). Preoperative Japanese Orthopedic Association scores ranged from 5.5 to 12 points with an average of 8.75 in this series.

\section{Image procedures}

All examinations were performed between 2010 and 2013 using a magnetic resonance imager (Achieva 3.0-T; Philips Medical System, Eindhoven, the Netherlands) equipped with a 16-channel neurovascular coil.

For anatomical and diagnostic imaging of the spine, T1- and T2-weighted images were acquired in the sagittal and axial planes. DTI data were obtained using an spin-echo-type single-shot echo-planar imagingsequence with the following parameters: echo time, $69 \mathrm{~ms}$; repetition time, $9079 \mathrm{~ms}$; number of slices, 30; interslice gap, $0 \mathrm{~mm}$; band width, $1711.8 \mathrm{~Hz}$ per pixel; voxel size, $1.79 \times 1.42 \times 4.00 \mathrm{~mm}$; acquisition matrix, $112 \times 140$; and NEX, 4 .

Images were obtained using $b$ values of 0 and $700 \mathrm{~s} \mathrm{~mm}^{-2}$.

A Philips MRI workstation was used to reconstruct ADC and FA maps from DTI data. Three eigenvalues $\left(\lambda_{1}, \lambda_{2}\right.$ and $\left.\lambda_{3}\right)$ were measured by averaging all selected pixels in the region of interest. ADC mean $=\left(\lambda_{1}+\lambda_{2}+\lambda_{3}\right) / 3=\lambda$ and FA was calculated with the following formula:

$$
\mathrm{FA}=\sqrt{\frac{2}{3}} \times \frac{\sqrt{\left(\lambda_{1}-\lambda\right)^{2}+\left(\lambda_{2}-\lambda\right)^{2}+\left(\lambda_{3}-\lambda\right)^{2}}}{\sqrt{\lambda_{1}{ }^{2}+\lambda_{2}{ }^{2}+\lambda_{3}{ }^{2}}} .
$$

These parameters were measured at five disc levels (from $\mathrm{C} 2 / \mathrm{C} 3$ to $\mathrm{C} 6 / \mathrm{C} 7$ ) on axial sections that gave stable values. Because DTI is not capable of capturing an image of plural stacks at one time, the image at each level were made parallel to $\mathrm{C} 4 / \mathrm{C} 5$ disc. (Figure 1)

\section{Region of interest setting and measurement}

After the appropriate axial slice was selected using the sagittal T2-weighted images for anatomic reference, a region of interest (ROI) was drawn manually on the spinal cord by an orthopedist. The ROI included both white and gray matter, excluding any cerebrospinal fluid contribution (Figure 2). The shape and size of each ROI varied according to the shape of the spinal cord, especially in patients with CSM.

\section{Intraoperative spinal cord-evoked potentials}

We measured three different kinds of SCEPs: SCEPs after median nerve stimulation, transcranial electric stimulations, and spinal cord stimulation SCEPs were recorded intraoperatively. The median nerves were stimulated (square wave pulse, $0.2 \mathrm{~ms}$ duration, $3 \mathrm{~Hz}$ rate) at wrist with the cathode placed proximally. The stimulus intensity was set at 1.5 times for producing the thumb twitch in an awakened condition. Transcranial electric stimulation was delivered as square pulses of $0.2 \mathrm{~ms}$ duration and at an intensity of $100 \mathrm{~mA}$ through needle electrodes (13R25, length $8 \mathrm{~mm}$, diameter $0.8 \mathrm{~mm}$, Dantec, Skovlunde, Denmark) placed on skull. The anode was placed $7 \mathrm{~cm}$ laterally to the right of the vertex on line joining the external auditory meatus. The cathode was placed on the opposite side. Spinal cord stimulation-SCEPs were delivered by an epidural catheter electrode(UKG-100-2PM, diameter $0.8 \mathrm{~mm}$, length $900 \mathrm{~mm}$, Unique Medical corporation, Japan) inserted into the dorsal epidural space from the C7-T1 interlaminar space. Square wave pulse $(0.2 \mathrm{~ms}$ duration, $3 \mathrm{~Hz}$ rate) were delivered at an intensity of 15-20 mA. Before laminoplasty, all SCEPs were recorded intraoperatively with recording electrodes (13R25) inserted in the ligamentum flavum at each interlaminar space, from $\mathrm{C} 2 / \mathrm{C} 3$ to $\mathrm{C} 7 / \mathrm{T} 1$. A reference electrode was inserted into the subcutaneous tissue in the posterior aspect of the neck for the recording of median nerve stimulations and Spinal cord stimulation-SCEPs. All SCEPs signals were amplified and filtered with a bandpass of $20-3000 \mathrm{~Hz}$ using a standard evoked potential/electromyography machine (Nicolet Viking, Nicolet Biomedical, Madison, WI, USA). Average of 100-200 median nerve stimulations, 40-60 Transcranial electric

Table 1 The findings on neurological examination of each CSM subject

\begin{tabular}{|c|c|c|c|c|c|c|c|c|c|c|c|c|c|c|}
\hline \multirow[t]{3}{*}{ Case } & \multirow[t]{3}{*}{$B T R$} & \multirow[t]{3}{*}{ TTR } & \multirow{3}{*}{$\begin{array}{l}\text { Uppermost muscle } \\
\text { with weakness }\end{array}$} & \multicolumn{10}{|c|}{ Sensory disturbance (at each dermatome) } & \multirow{3}{*}{$\begin{array}{l}\text { Segmental level of } \\
\text { dysfunction with } \\
\text { neurological exam } \\
\text { (disc level) }\end{array}$} \\
\hline & & & & \multicolumn{5}{|c|}{ Light touch } & \multicolumn{5}{|c|}{ Pin prick } & \\
\hline & & & & C5 & $C 6$ & $C 7$ & C8 & $T 1$ & C5 & C6 & $C 7$ & C8 & $T 1$ & \\
\hline 1 & $\rightarrow$ & $\uparrow$ & Triceps & - & - & + & + & + & - & - & + & + & + & $\mathrm{C} 4 / 5$ \\
\hline 2 & $\downarrow$ & $\uparrow$ & Deltoid & - & + & + & + & - & - & + & + & + & - & $\mathrm{C} 4 / 5$ \\
\hline 3 & $\downarrow$ & $\uparrow$ & (none) & - & + & + & + & + & - & + & + & + & - & $\mathrm{C} 4 / 5$ \\
\hline 4 & $\uparrow$ & $\uparrow$ & Biceps & - & + & + & + & - & - & + & + & + & - & $\mathrm{C} 3 / 4$ \\
\hline 5 & $\uparrow$ & $\uparrow$ & (none) & - & + & + & + & + & - & + & + & + & + & C3/4 \\
\hline 6 & $\uparrow$ & $\uparrow$ & Biceps & - & + & + & + & + & - & + & + & + & + & $\mathrm{C} 3 / 4$ \\
\hline 7 & $\rightarrow$ & $\uparrow$ & Deltoid & - & + & + & + & - & - & + & + & + & - & C4/5 \\
\hline 8 & $\downarrow$ & $\uparrow$ & Deltoid & + & - & - & - & - & + & - & - & - & - & C4/5 \\
\hline 9 & $\rightarrow$ & $\rightarrow$ & Triceps & - & - & + & + & + & - & - & - & + & + & $\mathrm{C} 5 / 6$ \\
\hline 10 & $\uparrow$ & $\uparrow$ & (none) & + & + & + & + & + & + & + & + & + & + & $\mathrm{C} 3 / 4$ \\
\hline
\end{tabular}


Table 2 Japanese Orthopedic Association Scoring System for Cervical Myelopathy

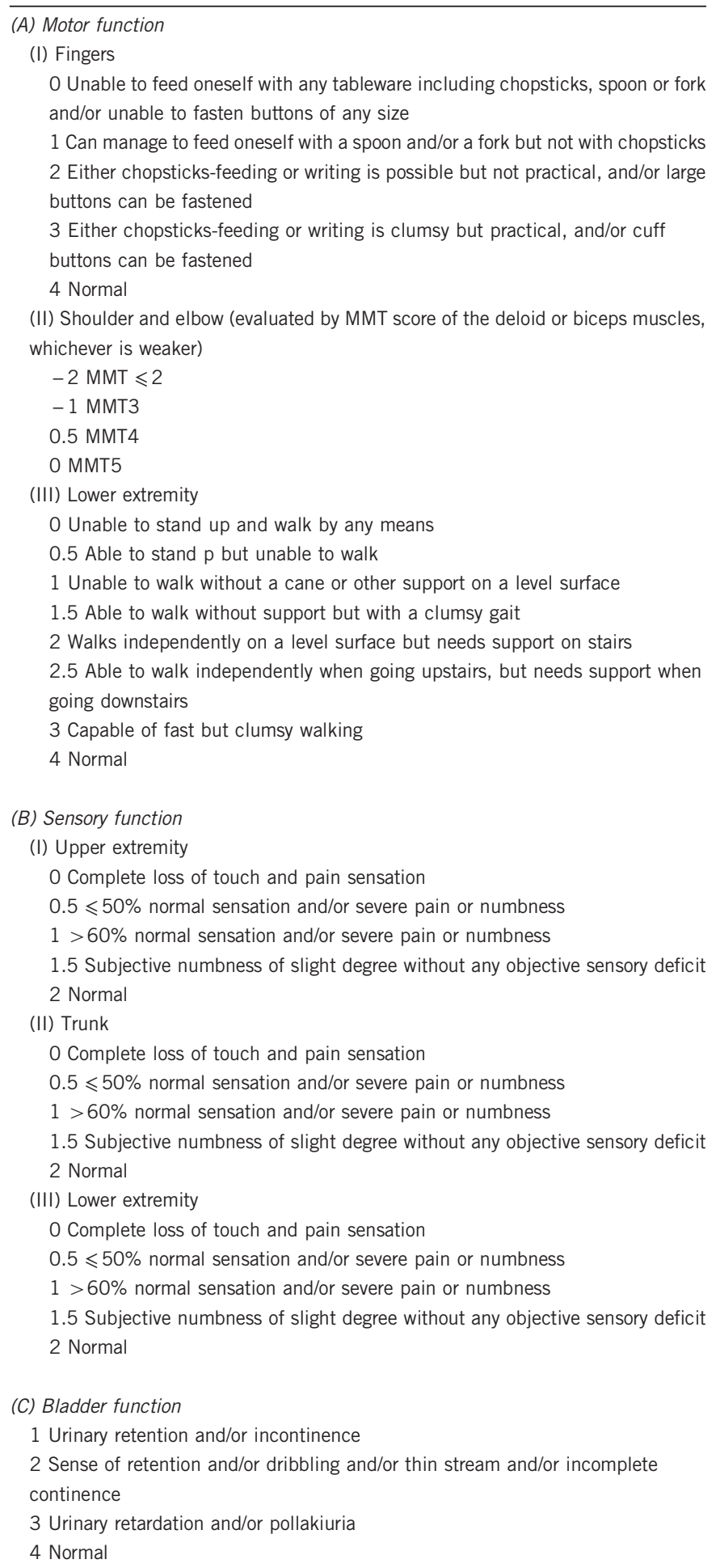

Abbreviation: MMT, manual muscle test.

Total for normal patient: 17 points.

stimulation-SCEPs and 20-30 Spinal cord stimulation-SCEPs responses were obtained and superimposed.

Abnormality was determined with a reduction of $>30 \%$ in size of negative peak compared with that of the $66 / 7$ intervertebral level in median nerve stimulations, and a reduction of $>50 \%$ compared with the disc level immediately above (in SCEPs after transcranial electric stimulations) or below (in SCEPs after stimulation to the spinal cord). ${ }^{6-8}$ An example of intraoperative SCEPs was shown in Figure 3.

\section{Statistical analysis}

Excel software (Microsoft, Tokyo, Japan) was used for statistical analysis. Statistically significant difference between the two groups were determined using the Mann-Whitney $U$-test. $P<0.05$ was considered statistically significant.

\section{RESULTS}

Comparison of diffusion tensor imaging parameters between normal and cervical spondylotic myelopathy subjects

The mean values and s.d. of the ADC and FA at five disc levels are shown in Table 3. The average ADC value of at all five disc levels had no significance between normal and CSM subjects $\left(1119 \pm 118 \times 10^{-6}\right.$ vs $1233 \pm 234 \times 10^{-6} \mathrm{~mm}^{2} \mathrm{~s}^{-1}$, respectively; $\left.P=0.205\right)$. The average FA value differed significantly between normal and CSM subjects $(0.66 \pm 0.06$ vs $0.59 \pm 0.05$, respectively; $P=0.024)$.

Relationship between diffusion tensor imaging parameters and the segmental level of spinal cord dysfunction

On conventional MRI, three subjects had single-level intervertebral compression and seven patients had multilevel. The compression level on conventional MRI, high signal change on T2 image, ADC and FA value at respective disc level are shown in Table 4.

All subjects were determined by SCEPs to have a single site of conduction abnormality, despite single- or multi-level compression. The segmental level of dysfunction was $\mathrm{C} 3 / \mathrm{C} 4$ in five cases and $\mathrm{C} 4 / \mathrm{C} 5$ in five cases. For all subjects with single-level compression and six of seven with multi-level compression, the ADC was maximal at the segmental level of dysfunction. The FA was minimal at the segmental level of dysfunction in two of three subjects with single-level compression and only two of seven subjects with multi-level compression (Table 5).

\section{DISCUSSION}

The maximal ADC value was observed at the segmental level corresponding to the site of dysfunction according to SCEP for all three subjects with single-level compression and six of seven with multi-level compression. Minimum FA values were observed at those same sites in two of three patients with single-level compression and in only two of three with multi-level compression.

Normal DTI-parameter values obtained from healthy subjects vary by individual factors such as age, environment under which measurements are taken, and ROI location. ${ }^{9,10}$ In subjects with CSM, the degree of the tissue injury differs between patients. Therefore, when comparing normal and CSM subjects, normal variability in measurements must be taken into consideration. In the present study, we measured the parameter values at five disc levels within each patient, with the normal regions of the spinal cord providing internal control data. Thus, normal variability between subjects does not affect our data analysis.

Decreased FA values generally indicate axonal damage, that is, degeneration of white matter in the brain and spinal cord. ${ }^{11}$ Unlike the brain, transverse sections of spinal cord are small and have poor image resolution, presenting a technical challenge for the investigation of ROIs close to the funiculi (for example, lateral and posterior funiculi). As described in previous reports, ROI was drawn on the spinal cord as wide as possible to include both gray matter and white matter, while 

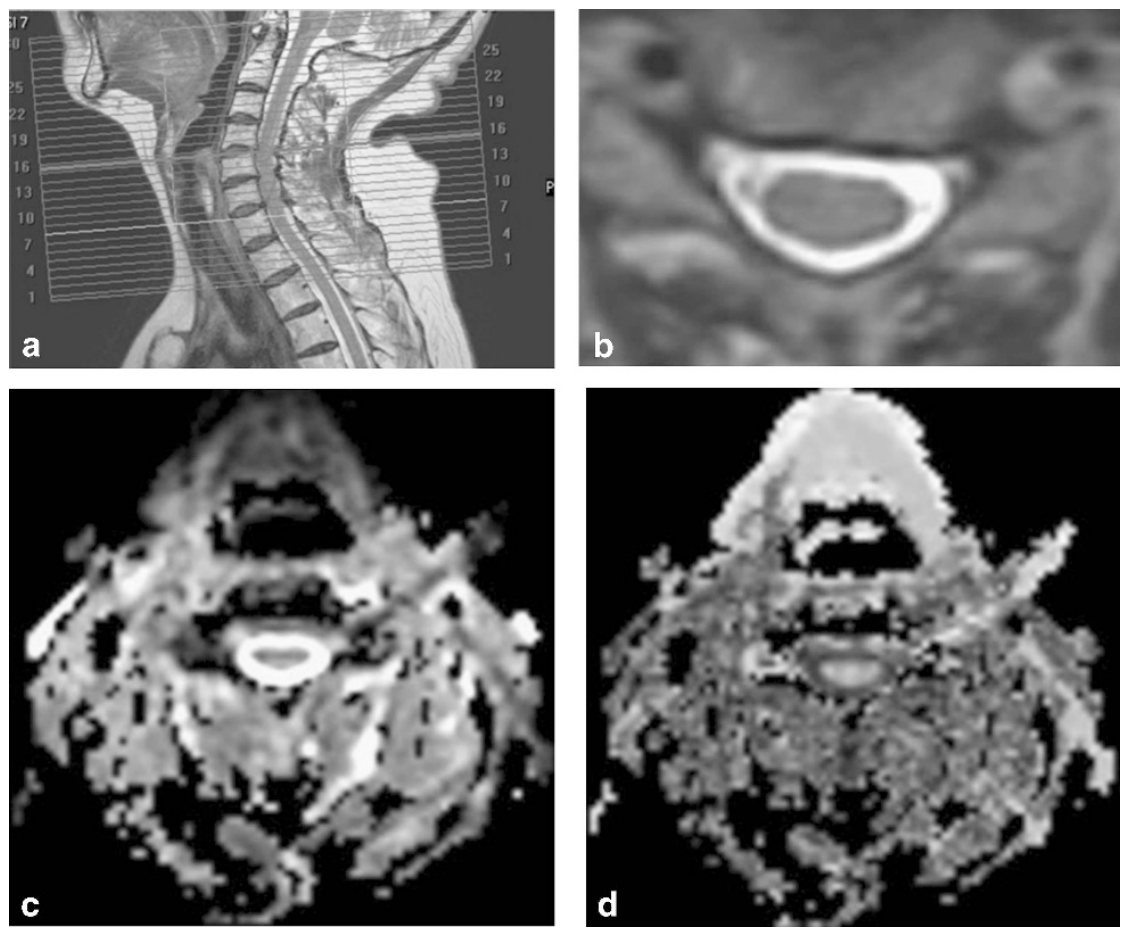

Figure 1 Basic images on DTI analysis. (a) Anatomical scan (T2-weighted fast spin echo image). Because DTI is not capable of capturing an image of plural stacks at one time, the image of each level is made parallel to C4/5 disc. (b) Conventional T2-weighted axial image. (c) ADC map (axial view). The CSF is shown with high signal intensity. (d) FA map (axial view). The CSF is shown with low signal intensity. Compared with conventional T2 image, the border of spinal cord is unclear in ADC and FA map.
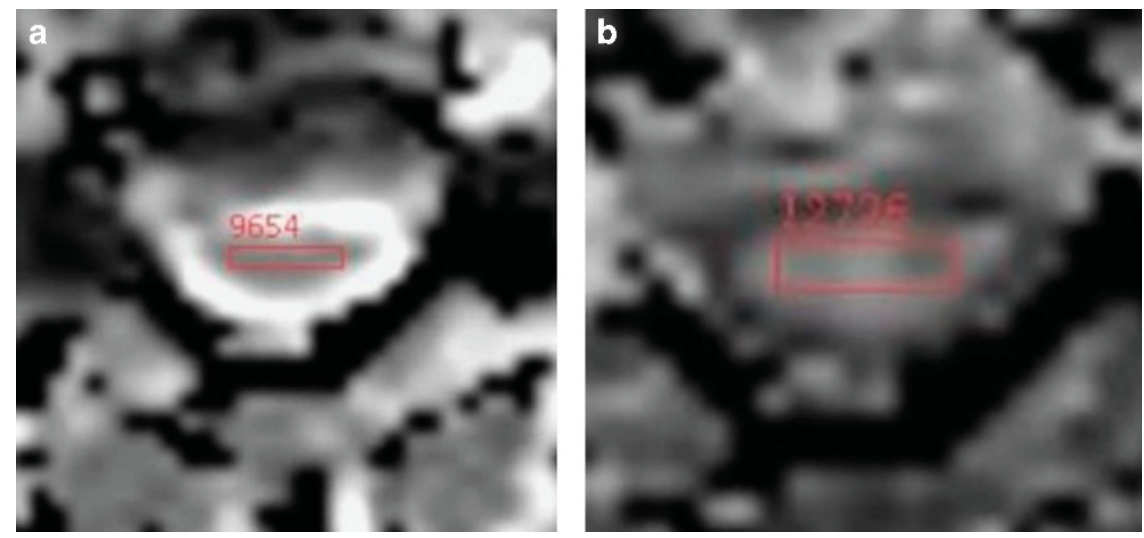

Figure 2 ROI setting in ADC map (a) and in FA map (b). The ROI is quadrangle, including both white matter and gray matter, excluding any cerebrospinal fluid (CSF) contribution.

excluding the cerebrospinal fluid. ROIs were analyzed one per disc level. The shape of each ROI varied according to the shape of the spinal cord. So the number of pixels, total pixel area, how much gray and how much white matter was included in respective ROI were also varied per slice and subject. It is ideal that whole gray and white matter are included in respective ROI in each axial plane of the spinal cord. But, considering the spatial resolutions that are currently possible, oversize ROI may have the risk of including cerebrospinal fluid. ${ }^{4,9,12}$

The cause of the observed increase in ADC in compressive cervical myelopathy is still uncertain. Compression of spinal cord leads to ischemia, anoxemia and cell membrane injury that can increase cell membrane penetrability, ${ }^{3,13,14}$ a possible source of the increased ADC. ADC elevation that occurs before signal elevation on T2-weighted images may indicate early myelopathy-related changes. ${ }^{10}$ This change is thought to reflect edema in the tissues. Conflicting data have been reported regarding whether the ADCs of compressed spinal cord regions vary significantly between levels of spinal cord. ${ }^{3,12}$ Difference in these results may arise from differing degrees of tissue injury between patients.

ADC and FA do not necessarily correlate. ${ }^{2}$ For example, a patient recovering from a stroke may have damaged fibers in the affected region of the brain, with stabilization of the surrounding tissues by gliosis. In this case, the FA values would be lower than normal, but the ADC values might not be elevated. ${ }^{15,16}$ In case of severe compressive cervical myelopathy, FA values decrease, sometimes without a corresponding increase in $\mathrm{ADC}$. Thus, the use of $\mathrm{ADC}$ values alone 


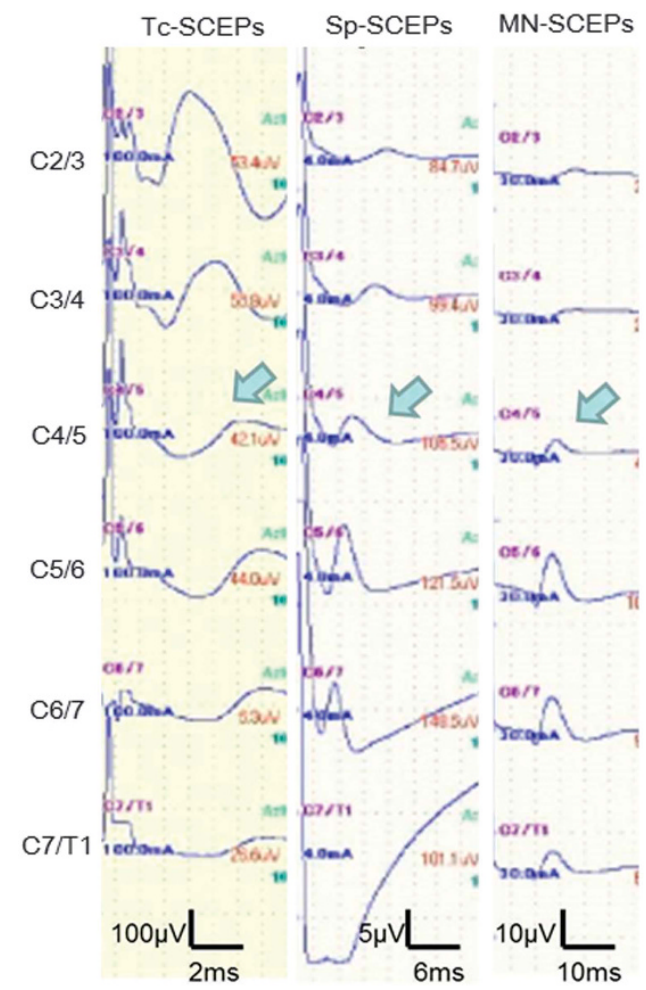

Figure 3 Intraoperative SCEPs in myelopathy of C4/5 level. In transcranial electric stimulations (TC-SCEPs), the amplitude at C4/5 level decreased $\geqslant 50 \%$ compared with C3/4. In spinal cord-evoked potential after stimulation to the spinal cord (Sp-SCEPs), the amplitude at C4/5 level decreased $\geqslant 50 \%$ compared with $\mathrm{C} 5 / 6$. In median nerve stimulation (MN-SCEPs), the amplitude at $\mathrm{C} 4 / 5$ decreased $\geqslant 30 \%$ compared with $\mathrm{C} 6 / 7$.

Table 3 Comparison of mean ADC and mean FA values of the whole 5 disc levels, between normal subjects and patients with cervical spondylotic myelopathy

\begin{tabular}{lccr}
\hline & Normal subjects $(n=11)$ & Patients with CSM ( $n=10)$ & P-value \\
\hline Mean ADC value & $1119 \pm 118$ & $1233 \pm 234$ & 0.205 \\
Mean FA value & $0.663 \pm 0.06$ & $0.598 \pm 0.05$ & 0.024 \\
\hline Abbreviations: ADC, apparent diffusion coefficient; CSM, cervical spondylotic myelopathy; \\
$\begin{array}{l}\text { FA, fractional anisotropy. } \\
\text { Mann-Whitney U-test. Values are mean } \pm \text { s.d. The unit of ADC: } 10^{-6} \mathrm{~mm}^{2} \mathrm{~s}^{-1}\end{array}$
\end{tabular}

to judge the presence or absence of spinal cord disorder is reportedly difficult. ${ }^{2,17}$ We think that intraoperative electrophysiological examination gives objective assessment of the affected segmental level and degree of myelopathy in CSM. ${ }^{18}$ We thus linked preoperative DTI analysis to the electrophysiological test results to increase the objectivity of the evaluation based on DTI parameters.

Comparison of the segmental level of CSM with ADC and FA revealed $\mathrm{ADC}$ was maximal at the level of spinal disorder in many cases, regardless of the extent of compression (single vs multi-level). In one case (No. 4), the maximum ADC and minimum FA were seen at the C6/C7 intervertebral level, whereas the level of dysfunction by intraoperative SCEPs was $\mathrm{C} 3 / \mathrm{C} 4$. In this case, there was severe compression of spinal cord at $\mathrm{C6} / \mathrm{C} 7$, and a decrease in SCEP was seen at the corresponding level. In another case (No. 10), compression of the spinal cord was seen at the $\mathrm{C} 3 / \mathrm{C} 4$ and $\mathrm{C} 5 / \mathrm{C} 6$, and the level of dysfunction was at $\mathrm{C} 3 / \mathrm{C} 4$. However, the minimum FA was at $\mathrm{C} 4 / \mathrm{C} 5$.

A previous study reported a decrease in FA both at the site of maximal compression and at sites distant to it. ${ }^{4}$ Furthermore, the minimum FA did not necessarily concur with the maximal compression level, particularly in cases involving multilevel compression. These findings may reflect that CSM-associated demyelination and axonal damage affect both the myelopathic lesion site and distal sites over the course of the disease. ${ }^{19,20}$

In four cases (No. 2, 5, 6 and 9), the minimum FA was observed at $\mathrm{C6} / \mathrm{C} 7$, even though this site had no compression and was distant from the lesion. Therefore, the results of our study indicate the FA is not useful as an objective diagnostic indicator of the segmental level of myelopathy.

The reason for increase in ADC at injury site is still not clear. However, if the ischemia, degeneration and inflammation caused by chronic compression of the spinal cord increase the ADC, it is reasonable that the level of dysfunction would correspond to the site with maximal histological damage. Our results suggest the ADC could be used as a supportive tool for diagnosing the level of myelopathy in CSM.

There are some limitations in the present study. First, this study is preliminary because of the small sample size. Further conclusions require future studies using a larger number of cases. Second, the axial images at each segmental level were made parallel to C4/C5 disc. This may affect the value of DTI parameters, especially FA that influenced by directionality. Third, how much gray matter and how much white matter were included in each ROI are varies per slice and subject. This might have introduced some bias. Fourth, we cannot compare the

Table 4 The findings on conventional MRI, preoperative JOA score and values of DTI parameters of each disc level in all CSM subjects

\begin{tabular}{|c|c|c|c|c|c|c|c|c|c|c|c|c|c|}
\hline \multirow[t]{2}{*}{ Case } & \multirow{2}{*}{$\begin{array}{l}\text { Compression } \\
\text { level on MRI }\end{array}$} & \multirow{2}{*}{$\begin{array}{c}\text { High signal } \\
\text { change on T2 image }\end{array}$} & \multirow{2}{*}{$\begin{array}{c}\text { JOA score } \\
\text { (preoperation) }\end{array}$} & \multicolumn{5}{|c|}{ ADC value $\left(10^{-6} \mathrm{~mm} \mathrm{~s}^{-1}\right)$} & \multicolumn{5}{|c|}{ FA value } \\
\hline & & & & $\mathrm{C} 2 / 3$ & $\mathrm{C} 3 / 4$ & $\mathrm{C} 4 / 5$ & $\mathrm{C} 5 / 6$ & $\mathrm{C} 6 / 7$ & $\mathrm{C} 2 / 3$ & $\mathrm{C} 3 / 4$ & $\mathrm{C} 4 / 5$ & C5/6 & C6/7 \\
\hline 1 & $\mathrm{C} 4 / 5$ & $\mathrm{C} 4 / 5$ & 11 & 1037 & 1008 & 1412 & 1374 & 1248 & 0.631 & 0.676 & 0.502 & 0.614 & 0.58 \\
\hline 2 & $\mathrm{C} 4 / 5$ & - & 9 & 1024 & 853 & 1045 & 829 & 877 & 0.69 & 0.705 & 0.604 & 0.721 & 0.583 \\
\hline 3 & $\mathrm{C} 4 / 5$ & $C 4 / 5$ & 10 & 859 & 860 & 1089 & 833 & 853 & 0.745 & 0.721 & 0.51 & 0.65 & 0.652 \\
\hline 4 & C3/4,6/7 & $\mathrm{C} 3 / 4$ & 9 & 1183 & 1313 & 1214 & 1005 & 1829 & 0.595 & 0.545 & 0.6 & 0.569 & 0.412 \\
\hline 5 & $\mathrm{C} 3 / 4,4 / 5$ & $\mathrm{C} 3 / 4$ & 9 & 1082 & 2106 & 1755 & 1182 & 1334 & 0.626 & 0.605 & 0.626 & 0.652 & 0.366 \\
\hline 6 & $\mathrm{C} 3 / 4,4 / 5$ & $\mathrm{C} 3 / 4$ & 7 & 1101 & 1670 & 1594 & 1405 & 1292 & 0.684 & 0.685 & 0.681 & 0.48 & 0.417 \\
\hline 7 & $\mathrm{C} 3 / 4,4 / 5$ & $\mathrm{C} 3 / 4$ & 6.5 & 1071 & 1139 & 907 & 1007 & 982 & 0.593 & 0.566 & 0.641 & 0.686 & 0.632 \\
\hline 8 & $\mathrm{C} 3 / 4,4 / 5,5 / 6$ & $\mathrm{C} 4 / 5$ & 8.5 & 1005 & 1188 & 1486 & 1427 & 1086 & 0.54 & 0.978 & 0.539 & 0.582 & 0.625 \\
\hline 9 & $\mathrm{C} 4 / 5,5 / 6$ & $\mathrm{C} 4 / 5,5 / 6$ & 12 & 1106 & 989 & 3155 & 1528 & 1259 & 0.721 & 0.639 & 0.593 & 0.685 & 0.574 \\
\hline 10 & C3/4,5/6 & C3/4,5/6 & 5.5 & 1227 & 1415 & 1093 & 1198 & 1143 & 0.531 & 0.488 & 0.435 & 0.503 & 0.548 \\
\hline
\end{tabular}

Abbreviations: ADC, apparent diffusion coefficient; CSM, cervical spondylotic myelopathy; DTI, diffusion tensor imaging; FA, fractional anisotropy; JOA, Japanese Orthopedic Association; $\mathrm{MRI}$, magnetic resonance imaging 
Table 5 Matching of electrophysiological data and values of DTI parameters

\begin{tabular}{|c|c|c|c|c|c|c|c|}
\hline \multirow[t]{2}{*}{ Case } & \multicolumn{3}{|c|}{ The disc level of conduction block in each SCEP } & \multirow{2}{*}{$\begin{array}{c}\text { The disc level of } \\
\text { maximal } A D C\end{array}$} & \multirow{2}{*}{$\begin{array}{l}\text { Matching } \\
\text { (ADC and SCEP) }\end{array}$} & \multirow{2}{*}{$\begin{array}{c}\text { The disc level of } \\
\text { minimal FA }\end{array}$} & \multirow{2}{*}{$\begin{array}{l}\text { Matching } \\
\text { (FA and SCEP) }\end{array}$} \\
\hline & MN-SCEPS & $T C-S C E P S$ & $S p-S C E P S$ & & & & \\
\hline 2 & $\mathrm{C} 4 / 5$ & $\mathrm{C} 4 / 5$ & $\mathrm{C} 4 / 5$ & $\mathrm{C} 4 / 5$ & matched & $\mathrm{C} 6 / 7$ & - \\
\hline 3 & $\mathrm{C} 4 / 5$ & $\mathrm{C} 4 / 5$ & $\mathrm{C} 4 / 5$ & $C 4 / 5$ & matched & $\mathrm{C} 4 / 5$ & matched \\
\hline 4 & $\mathrm{C} 3 / 4$ & $\mathrm{C} 3 / 4$ & $\mathrm{C} 3 / 4$ & $\mathrm{C} 6 / 7$ & - & $\mathrm{C} 6 / 7$ & - \\
\hline 7 & $\mathrm{C} 3 / 4$ & $\mathrm{C} 3 / 4$ & $\mathrm{C} 3 / 4$ & $\mathrm{C} 3 / 4$ & matched & $\mathrm{C} 3 / 4$ & matched \\
\hline 8 & $\mathrm{C} 4 / 5$ & $\mathrm{C} 4 / 5$ & $C 4 / 5$ & $\mathrm{C} 4 / 5$ & matched & $C 4 / 5$ & matched \\
\hline 9 & $\mathrm{C} 4 / 5$ & $\mathrm{C} 4 / 5$ & $\mathrm{C} 4 / 5$ & $\mathrm{C} 4 / 5$ & matched & $\mathrm{C} 6 / 7$ & - \\
\hline 10 & $\mathrm{C} 3 / 4$ & $\mathrm{C} 3 / 4$ & $\mathrm{C} 3 / 4$ & $\mathrm{C} 3 / 4$ & matched & $\mathrm{C} 4 / 5$ & - \\
\hline
\end{tabular}

Abbreviations: ADC, apparent diffusion coefficient; DTI, diffusion tensor imaging; FA, fractional anisotropy; MN-SCEPs; spinal cord-evoked potential after median nerve stimulation, SCEP, spinal cord-evoked potential; Sp-SCEPs, spinal cord-evoked potential after stimulation to the spinal cord; Tc-SCEPs, spinal cord-evoked potential after transcranial electric stimulation.

change of ADC and FA value with histopathological change in the spinal cord. So the cause of change in these parameters was still speculative. Fifth, it has not been completely proved that intraoperative SCEPs allow to unequivocally reflect the integrity of respective cervical segments. Ideally, needle electromyography of muscles corresponding to each cervical myotome should have been employed. In the case No. 9, neurological level diagnosis with physical examination was C5/C6, but the result from SCEPs and DTI was C4/C5. This case had multi-level compression(C4/C5 and C5/C6), and T2 high intensity at the same levels. We sometimes experience the difficulty in diagnosing the segmental level of dysfunction with physical examination and conventional MRI with multi-level compression. As Seichi et al. reported, the average accuracy of neurologic level diagnosis based on the index was $\geqslant 70 \% .^{5}$ In the case of multi-level CSM, sensitivity, specificity and accuracy of neurological diagnosis might be lower. In such case, the neurological level diagnosis can be more accurate by use of needle electromyography.

We observed a correlation between the intervertebral level of maximal $\mathrm{ADC}$ and the segmental level responsible for CSM. The observed correlation between the maximal ADC and the segmental level of dysfunction according to SCEP indicates that ADC might serve as a supplementary diagnostic indicator of the segmental levels of dysfunction in CSM.

\section{DATA ARCHIVING}

There were no data to deposit.

\section{CONFLICT OF INTEREST}

The authors declare no conflicts of interest.

1 Facon D, Ozanne A, Fillard P, Lepeintre JF, Tournoux-Facon C, Ducreux D. MR diffusion tensor imaging and fiber tracking in spinal cord compression. AJNR Am J Neuroradiol 2005; 26: 1587-1594.

2 Yoo WK, Kim TH, Hai DM, Sundaram S, Yang YM, Park MS et al. Correlation of magnetic resonance diffusion tensor imaging and clinical findings of cervical myelopathy. Spine J 2013; 13: 867-876.

3 Song T, Chen WJ, Yang B, Zhao HP, Huang JW, Cai MJ et al. Diffusion tensor imaging in the cervical spinal cord. Eur Spine J 2011; 20: 422-428.
4 Wen CY, Cui JL, Liu HS, Mak KC, Cheung WY, Luk KD et al. Is diffusion anisotropy a biomarker for disease prognosis of cervical spondylotic myelopathy? Radiology 2014; 270: 197-204.

5 Seichi A, Takeshita K, Kawaguchi H, Matsudaira K, Higashikawa A, Ogata N et al. Neurological level diagnosis of cervical stenotic myelopathy. Spine 2006; 31: 1338-1343.

6 Kaneko K, Kawai S, Taguchi T, Fuchigami Y, Ito T, Morita H. Correlation between spinal cord compression and abnormal patterns of median nerve somatosensory evoked potentials in compressive cervical myelopathy: comparison of surface and epidurally recorded responses. J Neurol Sci 1998; 158: 193-202.

7 Kanchiku T, Taguchi T, Kaneko K, Fuchigami Y, Yonemura H, Kawai S. A correlation between magnetic resonance imaging and electrophysiological findings in cervical spondylotic myelopathy. Spine 2001; 26: 269-274.

8 Kaneko K, Taguchi T, Morita H, Yonemura H, Fujimoto H, Kawai S. Mechanism of prolonged central motor conduction time in compressive cervical myelopathy. Clin Neurophysiol 2001; 112: 1035-1040.

9 Uda T, Takami T, Tsuyuguchi N, Sakamoto S, Yamagata T, Ikeda H et al. Assessment of cervical spondylotic myelopathy using diffusion tensor magnetic resonance imaging parameter at 3.0 tesla. Spine 2013; 38: 407-414.

10 Mamata H, Jolesz FA, Maier SE. Apparent diffusion coefficient and fractional anisotropy in spinal cord: age and cervical spondylosis-related changes. J Magn Reson Imaging 2005; 22: 38-43.

11 Inano S, Takao H, Hayashi N, Abe O, Ohtomo K. Effects of age and gender on white matter integrity. AJNR Am J Neuroradiol 2011; 32: 2103-2109.

12 Hori M, Fukunaga I, Masutani Y, Nakanishi A, Shimoji K, Kamagata K et al. New diffusion metrics for spondylotic myelopathy at an early clinical stage. Eur Radiol 2012; 22: $1797-1802$.

13 Demir A, Ries M, Moonen CT, Vital JM, Dehais J, Arne P et al. Diffusion-weighted MR imaging with apparent diffusion coefficient and apparent diffusion tensor maps in cervical spondylotic myelopathy. Radiology 2003; 229: 37-43.

14 Mamata H, Jolesz FA, Maier SE. Characterizaion of central nervous system structures by magnetic resonance diffusion anisotropy. Neurochem Int 2004; 45: 553-560.

15 Thomalla G, Glauche V, Koch MA, Beaulieu C, Weiller C, Röther J. Diffusion tensor imaging detects early Wallerian degeneration of the pyramidal tract after ischemic stroke. Neuroimage 2004; 22: 1767-1774.

16 Werring DJ, Toosy AT, Clark CA, Parker GJ, Barker G, Miller D et al. Diffusion tensor imaging can detect and quantify corticospinal tract degeneration after stroke. J Neurol Neurosurg Psychiatry 2000; 69: 269-272.

17 Aota Y, Niwa T, Uesugi M, Yamashita T, Inoue T, Saito T. The correlation of diffusionweighted magnetic resonance imaging in cervical compression myelopathy with neurologic and radiologic severity. Spine 2008; 33: 814-820.

18 Kanchiku T, Imajo Y Suzuki H, Yoshida Y, Akashi K, Taguchi T. Correlation between spinal cord function assessed by intraoperative SCEPS and morphology of the compressed spinal cord on MRI. J Spinal Disord Tech 2013, e-pub ahead of print 6 November 2013, doi: 10.1097/BSD.0b013e318291cb61.

19 Urakawa T, Matsuzawa H, Suzuki Y, Endo N, Kwee IL, Nakada T. Analysis of ascending spinal tract degeneration in cervical spondylotic myelopathy using 3D anisotropy contrast single-shot echo planar imaging on a 3.0-T system. J Neurosurg Spine 2011: 15: 648-653.

20 Fehlings MG, Skaf G. A review of the pathophysiology of cervical spondylotic myelopathy with insights for potential novel mechanisms drawn from traumatic spinal cord injury. Spine 1998; 23: 2730-2737. 